\title{
Investigation of the Effect of Soil and Wall Interaction on the displacement of Retaining Walls Using Finite Element Method
}

\author{
Mojtaba Ahmadabadi ${ }^{*}$, Samad Hosseini ${ }^{2}$, Morteza Rezai ${ }^{3}$ \\ ${ }^{1}$ Lecturer and faculty member at Shiraz Art Institute of Higher Education, Shiraz, Iran \\ ${ }^{2}$ Graduate student at the University of Shiraz \\ ${ }^{3}$ Consulting Engineers of Civil Development of ancient Pasargad
}

\begin{abstract}
In this article, the effect of soil and wall interaction was investigated by finite element method. Eleven different models, with different foundations were studied. These studies can estimate displacement at any height of the wall for frictional-sticky soils. The main purpose of the present study was to determine the best conditions for the anchor and foundation of the wall to reduce wall displacement. Comparing the results of different models show that the overall increase in the depth and length of the foundation can reduce wall displacement. Greater effect in the reduction of wall displacement can be observed when the foundation is on the front of the wall compared to the condition when the embankment is behind the wall. Based on the results, two types of displacement are observed: Overturning and Bulging. The results show that clamping the wall base and disregarding the impact of the wall foundation produce unrealistic results. The advantage of this study is in considering all parameters of the soil and wall.
\end{abstract}

Keywords: Retaining wall, FEM, Soil and Wall Interaction, Angle of Internal Friction of the Soil, Wall Displacement.

\section{INTRODUCTION}

Computing wall displacement is among the important topics in geotechnical engineering and interaction of soil and wall. About retaining walls, two basic issues have important roles: the analysis and design of the wall. The first issue is related to geotechnical discussions and the second one is related to structural issues. The more precise the processes of the analysis and determination of the forces and the displacement degree, the more economical and efficient the design of the supporting structure. Therefore, the issue of analysis is of the most fundamental and most important issues of supporting structures. To study the deformation of walls three methods including laboratory studies, numerical and analytical methods are used. The most comprehensive analysis method in the investigation of the behavior of soil structures is numerical methods such as finite element and finite difference.

Cai and Bathurst (1995) examined the dynamic response of a soil retaining wall reinforced with geosynthetics using finite element analysis. Finite element mesh applied to the simulations included 651 elements and 652 knots. The wall height was $3.2 \mathrm{~m}$ and the wall dyke was grained and foundation of the walls were clamped. Hatami et al. (2001) analyzed 21 models of reinforced soil walls which were reinforced using several types of reinforcers at the height of the wall. Wall height

\footnotetext{
*Electronic address: Ahmadabadi@honarshiraz.ac.ir
} 
was considered 12 meters. Lee et al. (2010) studied three models of reinforced soil walls under seismic loading using numerical methods and used Kobe earthquake record for seismic input and the results were compared with three experimental models.

Bhattacharjee and Krishna(2010) studied the dynamic behavior of retaining walls reinforced with rigid surface modelled in FLAC three-dimensional software and compared the results of numerical simulations with the results of other scientists' laboratory models. They concluded that the horizontal displacement of reinforced walls substantially reduced compared to naked walls. In addition, reinforcement with low resistance can reduce displacement up to $44 \%$ compared to naked walls. Bourgieos et al. (2011) examined various displacement models under load service using the finite element numerical analysis. Finite element analysis was carried out for both flat and threedimensional strain. They concluded that displacement in the simulation was greater than the measured values in the experiment. Athanasopoulos et al. (2012) examined the effect of EPS geofoam compressibility in both parameters of seismic pressure and displacement of retaining walls using numerical analysis. Using numerical modelling, and PLAXIS - a two-dimensional finite element software - they examined the seismic response of the two retaining walls with the heights of 4 and 2.5 meters.

In this study, using the finite element method and with respect to all of the parameters of the soil, the effect of the depth of the wall and supporting conditions are examined. The main purpose of the study was to determine the best conditions of the anchor and foundation type of the wall to reduce wall displacement.

\section{Numerical Modeling}

Numerical modeling was carried out using Abaqus (6.12-1) finite element software. Abaqus is one of the most powerful simulation softwares that use finite element method. The model geometry is 2D and it is Type Deformable. The elastic and plastic characteristics of the walls and soil are selected according to Table 1 . The parameters $\mathrm{c}, \phi$ and $\psi$ respectively indicate cohesion, internal friction angle and dilation angle of the materials in Mohr-Clamp behavioral model. Model mesh is selected from Tri element type.

Table 1. Wall and soil parameters in Mohr-Clamp model in Ottawa sand

\begin{tabular}{|c|c|c|c|c|c|c|c|}
\hline \multirow[t]{2}{*}{ Soil } & $\begin{array}{l}\text { total unit weight } \\
\qquad(\mathrm{kN} / \mathrm{m} 3)\end{array}$ & $\begin{array}{l}\text { Modulus of } \\
\text { elasticity of } \\
\text { soil(pa) }\end{array}$ & $\begin{array}{c}\text { friction angle } \\
\text { between wall } \\
\text { and backfill } \\
\text { soil }\left(^{\circ}\right)\end{array}$ & $\begin{array}{c}\text { angle of } \\
\text { internal } \\
\text { friction of } \\
\text { soil }\left({ }^{\circ}\right)\end{array}$ & $\begin{array}{c}\text { cohesion } \\
\text { of soil } \\
(\mathrm{kPa})\end{array}$ & $\begin{array}{l}\text { Poisson's } \\
\text { ratio }\end{array}$ & $\begin{array}{l}\text { Dilation } \\
\text { Anggle }\end{array}$ \\
\hline & $\begin{array}{c}\gamma \\
20\end{array}$ & $\begin{array}{c}\mathrm{E} \\
182^{*} 10^{6}\end{array}$ & $\begin{array}{c}\delta \\
2 / 3 \phi\end{array}$ & $\begin{array}{c}\phi \\
30^{0}\end{array}$ & $\begin{array}{l}\chi \\
5\end{array}$ & $\begin{array}{c}v \\
0.3\end{array}$ & $\begin{array}{c}\psi \\
0.1 \\
\end{array}$ \\
\hline \multirow[t]{2}{*}{ Wall } & $\begin{array}{c}\text { Wall } \\
\text { thickness }(\mathrm{mm})\end{array}$ & $\begin{array}{l}\text { Modulus of } \\
\text { elasticity of } \\
\text { concrete(pa) }\end{array}$ & $\begin{array}{l}\text { total unit } \\
\text { weight } \\
(\mathrm{kN} / \mathrm{m} 3)\end{array}$ & $\begin{array}{l}\text { Poisson's } \\
\text { ratio }\end{array}$ & $\begin{array}{l}\text { height of } \\
\text { wall (m) }\end{array}$ & & \\
\hline & $\begin{array}{c}\delta \\
40\end{array}$ & $\begin{array}{c}\mathrm{E}_{\chi} \\
2.1 * 10^{10}\end{array}$ & $\begin{array}{l}\gamma_{\chi} \\
24\end{array}$ & $\begin{array}{c}v \\
0.2\end{array}$ & $\begin{array}{l}\mathrm{H} \\
10\end{array}$ & & \\
\hline
\end{tabular}

To study the effect of soil interaction and the effect of wall base foundation, 11 different models were examined. The results of the modified model of these 11 models are shown in Figures 1 to 4 . Each form is divided regarding the depth and width of the foundation wall in the soil. All models are with interaction effect of the soil under the wall except in a9 and a10 models which the base of the wall is clamped regardless of the effect of interaction with the soil under the foundation. In most models, deformation plate is linear. In a9 and a10 models, unlike all other models 
Bulletin de la Société Royale des Sciences de Liège, Vol. 85, 2016, p. 1 - 7

deformation plate does not happen in the wall base, but in the rest of the models, the deformation is in the wall base.
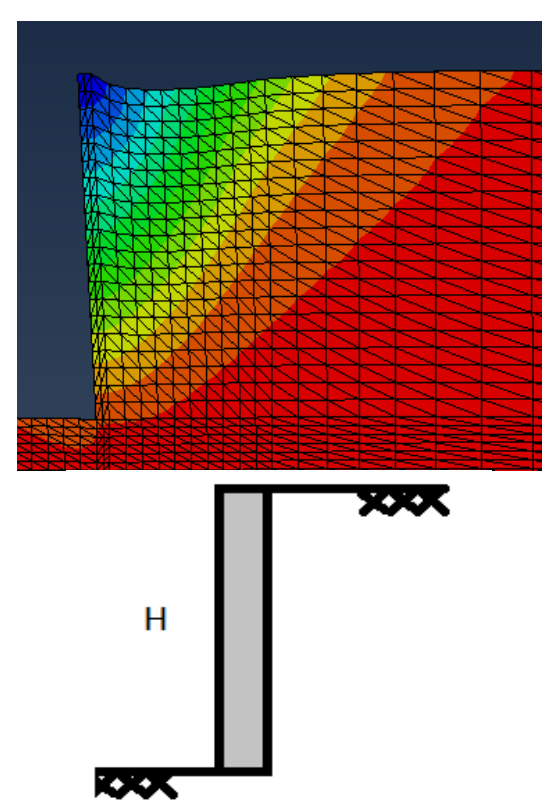

a1
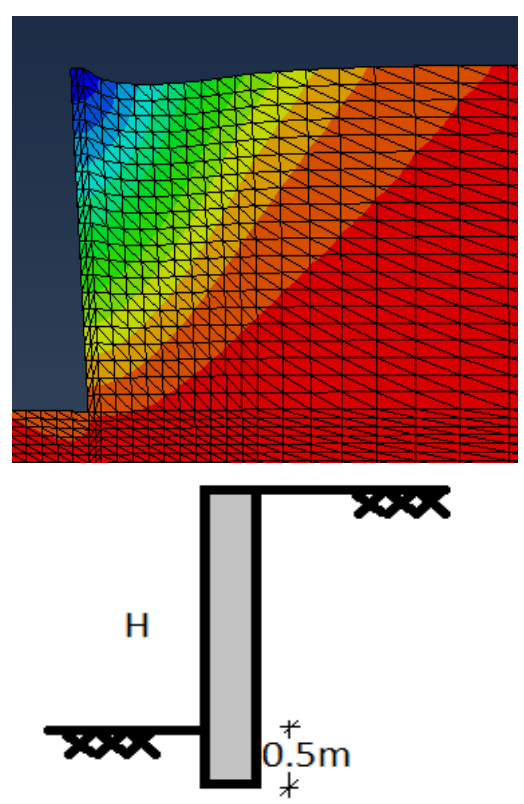

a2
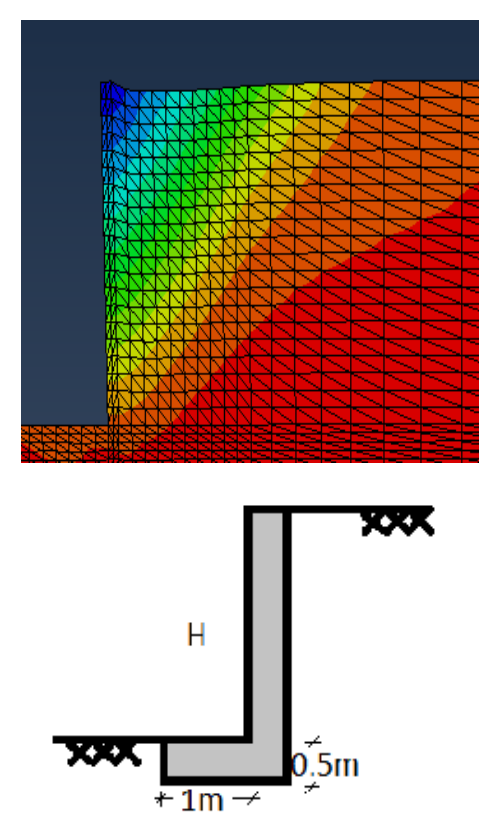

a3

Fig. 1. Deformed model with foundation changes of the wall for the three models: a1, a2 and a3
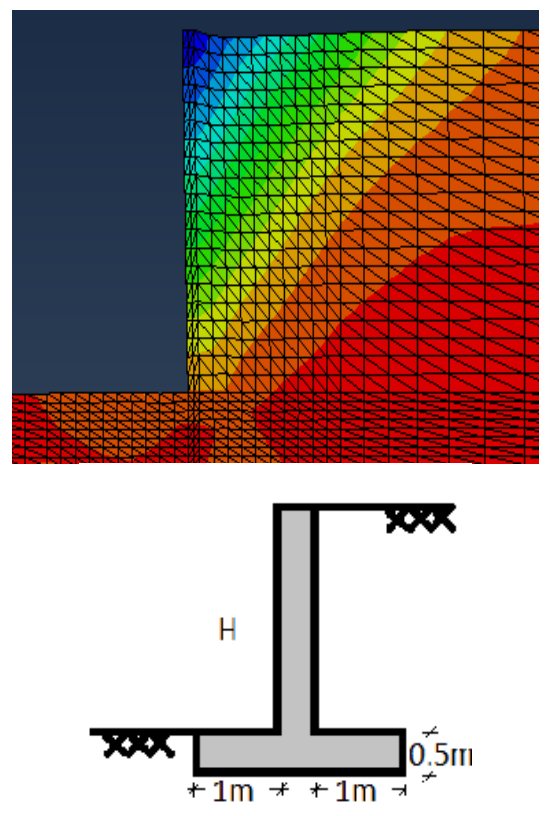

a4
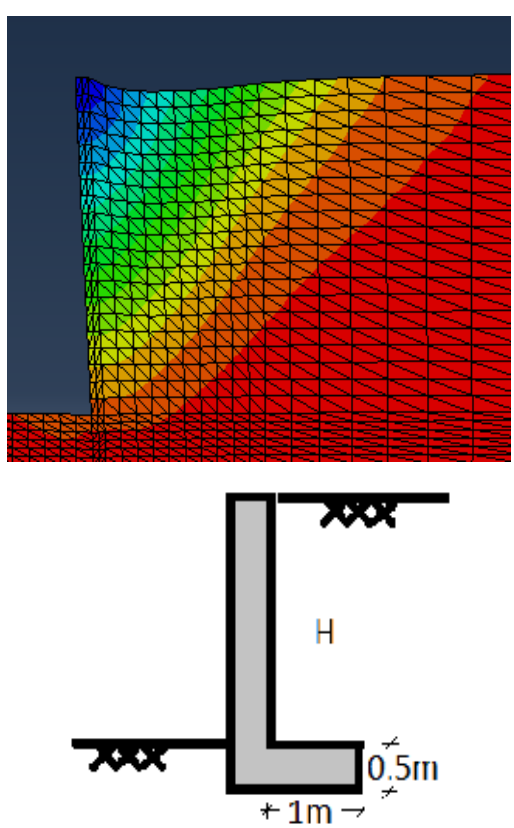

a5
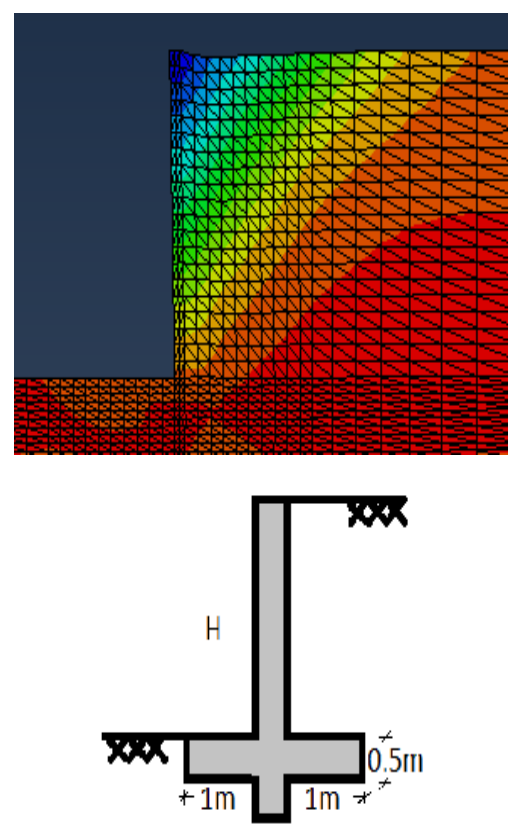

a6

Fig. 2. Deformed model with foundation changes of the wall for the three models: a4, a5 and a6 
Bulletin de la Société Royale des Sciences de Liège, Vol. 85, 2016, p. 1 - 7
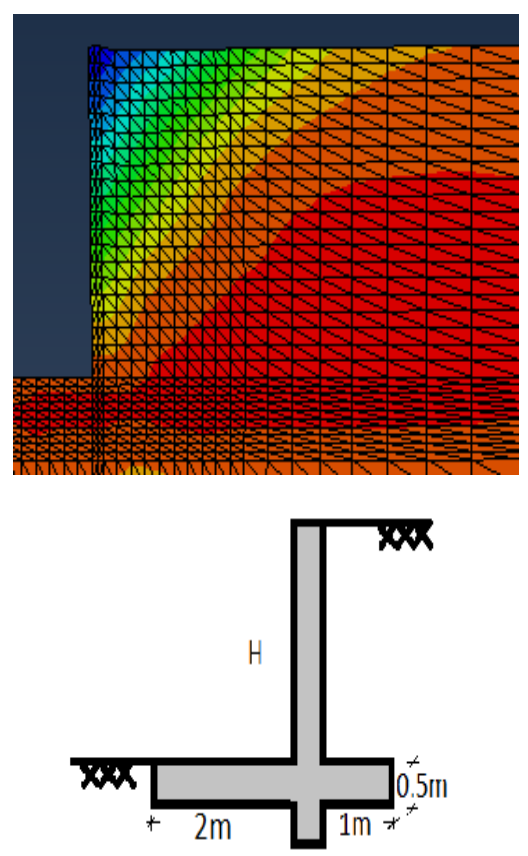

a7
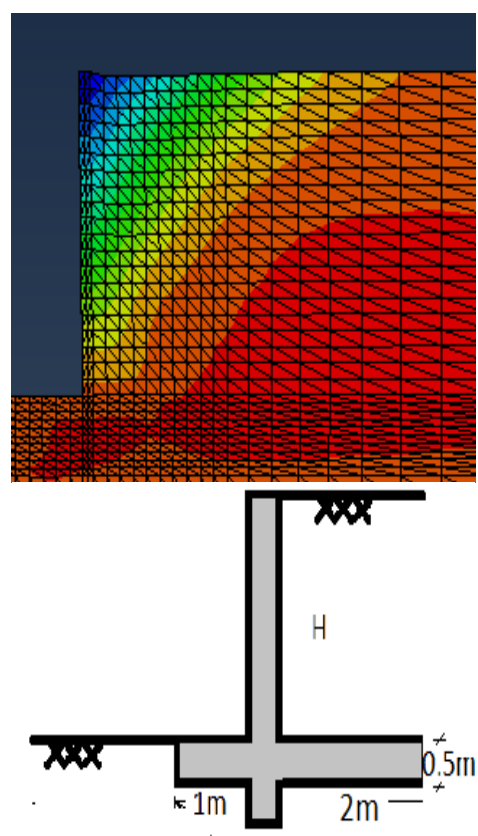

a8
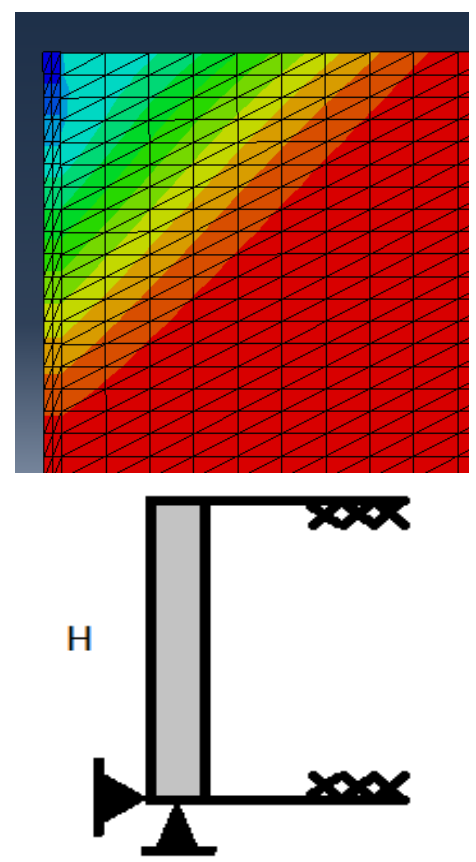

a9

Fig. 3. Deformed model with foundation changes of the wall for the three models: a7, a8 and a9
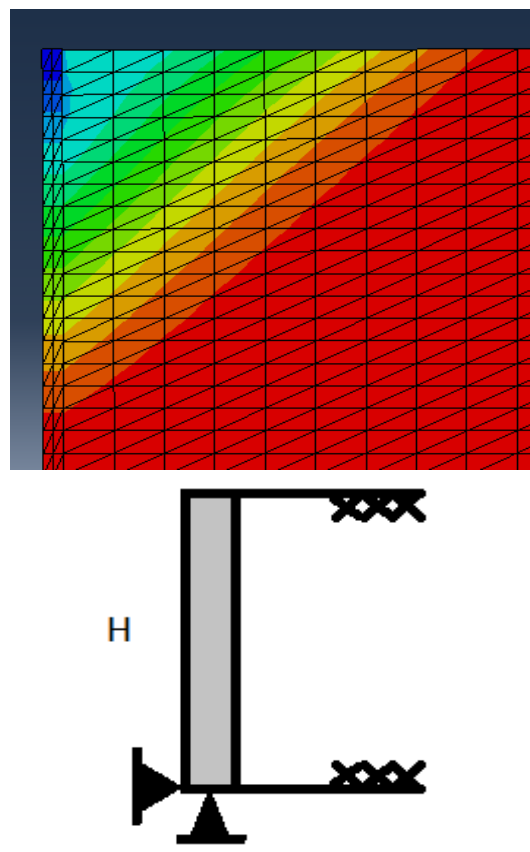

a10
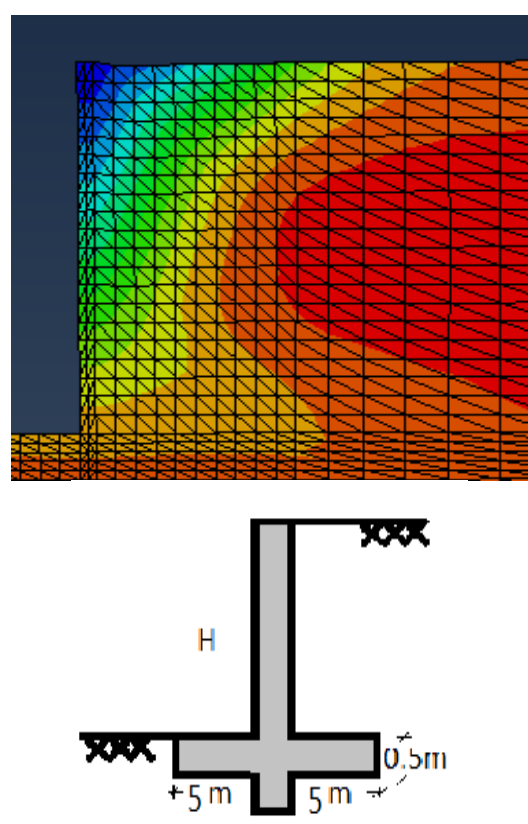

a11

Fig. 4. Deformed model with foundation changes of the wall for the two models: a11 and a10

Figure 5 shows the displacement distribution of 11 models. In general, increasing the depth and length of the foundation of wall base reduces displacement. Displacement distribution in all models is "Overturning". In a5 model the foundation direction is toward the backfill behind the wall. This study shows that the a3 model (symmetrically a5) reduces $47 \%$ of wall displacement and it is proposed to use a3 model. 
According to the models a4 and a6 the existence of the heel under wall does not effect wall displacement and it only reduces $3 \mathrm{~mm}$ of wall tip displacement. Increasing foundation length toward the embankment in front of the wall will reduce displacement and the impact is much more than increasing the length towards the embankment behind the wall (models a8 and a7). In model a10, the wall was investigated without the effect of the interaction of the wall base. Increasing the length of the foundation to 5 meters on each side could not produce similar results with the a10 condition and this shows the impact of the interaction of the soil in the wall base, ignoring which will make the results very unrealistic.

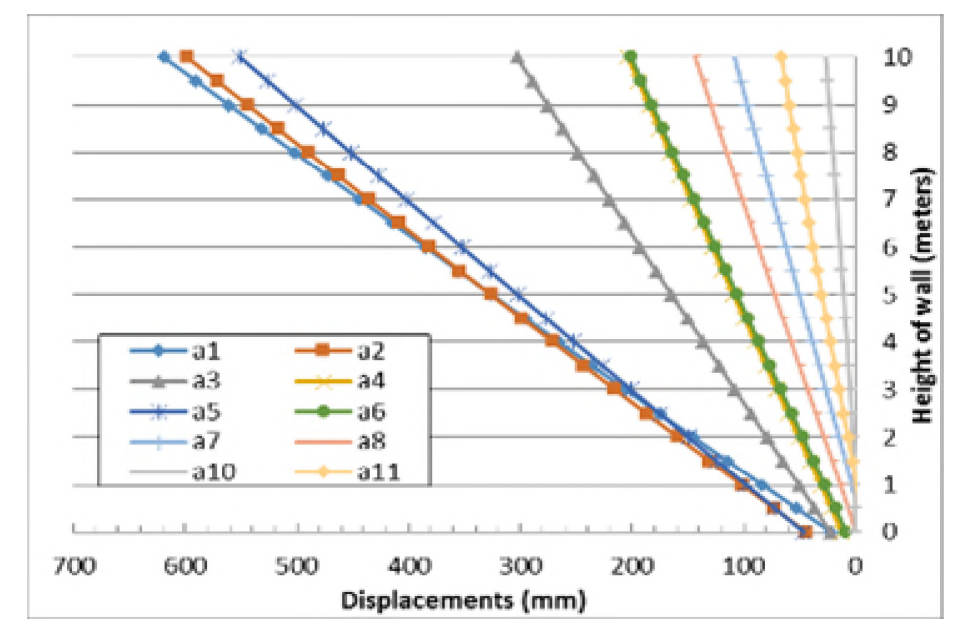

Fig. 5. Distribution of deformation in wall height comparing the interaction effect of soil and wall

Figure 6 shows the results of a9 and a10 models. In these two models, the walls and the soil are modeled separately and the impact of the interaction of soil and wall is used on their common border. In a9 model, the soil mass displacement on the common border with the wall and in the a10 model, wall displacement is shown. As is clear, displacement in the a9 model is of Bulging type and in the a10 model, the displacement type is Overturning.

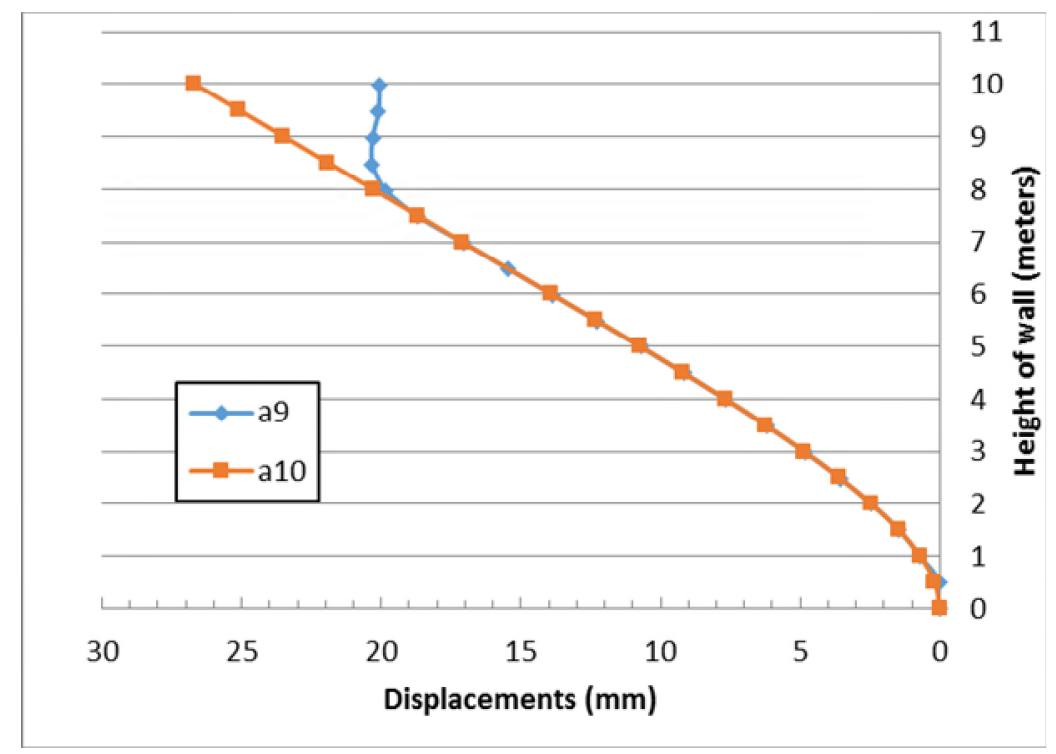

Fig. 6. Distribution of deformation in wall height comparing the interaction effect of the soil and wall 
Bulletin de la Société Royale des Sciences de Liège, Vol. 85, 2016, p. 1 - 7

\section{Conclusion}

Based on the investigations presented in this study, the following conclusions can be drawn:

1. Increasing the depth and length of the base of the wall foundation reduces the wall displacement.

2. In all models, displacement type is Overturning and in a9 model that wall and soil are modeled separately, soil mass displacement is Bulging and in the same model, displacement of the concrete wall is again Overturning.

3. When foundation of the wall is on the front side, displacement is notably reduced compared to the condition when it is behind the embankment.

4. The existence of clamping heel in the wall does not have a significant effect on reducing wall displacement.

5. Clamping the wall base produces unrealistic results, and the effect of the interaction between the foundation and the soil must be taken into consideration.

\section{REFERENCES}

[1] ABAQUS 6.10. 2010, Documentation, Dassault Systemes Simulia Corp., Providence, RI, USA. [2] ACI 318-05, Building Code Requirements for Structural Concrete and Commentary - ACI 318R-05, American Concrete Institute, Farming Hills, MI, USA, 2005.

[3] Athanasopoulos, A-Zekkos., Lamote, G., Athanasopoulos, G.A. (2012), "Use of EPS geofoam compressible inclusions for reducing the earthquake effects on yielding earth retaining structures," Soil Dynamics and Earthquake Engineering 41, pp 59-71.

[4] Bhattacharjee, A., Krishna, A. Murali. (2010), "Numerical modelling of rigid faced reinforced soil walls under seismic shaking," Indian Geotechnical Conference.

[5] Bourgeois, E., Soyez, L., Le Kouby, A. (2011), "Experimental and numerical study of the behavior of a reinforced-earth wall subjected to a local load". Computers and Geotechnics 38 (2011) 515-525.

[6] Lee, K.Z.Z., Chang, N.Y., Ko, H.Y. (2010). "Numerical simulation of geosynthetic-reinforced soil walls under seismic shaking," Geotextiles and Geomembranes, 28 (2010) 317-334.

[7] Hatami, K., Bathurst, R.J., Di Pietro, P. (2001), "Static response of reinforced soil retaining walls with nonuniform reinforcement," The International Journal of Geomechanics, Vol. 1, No. 4 (2001) 477-506.

[8] Cai, Z., Bathurst, R.J. (1995), "Seismic response analysis of geosynthetic reinforced soil segmental retaining walls by finite element method," Computers and Geotechnics 17 (1995) 523546. 